\title{
O\&A • Developing nations key to solving global food, resource problems
}

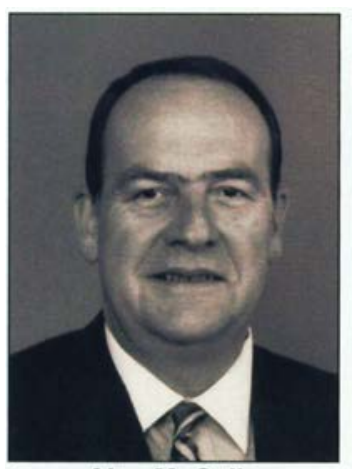

Alex McCalla

Population growth will occur primarily between the Tropics of Cancer and Capricorn, including Latin and Central America, most of Africa and southern India and Asia. At the U.S.J Mexico border south of San Diego, population has spurred development.

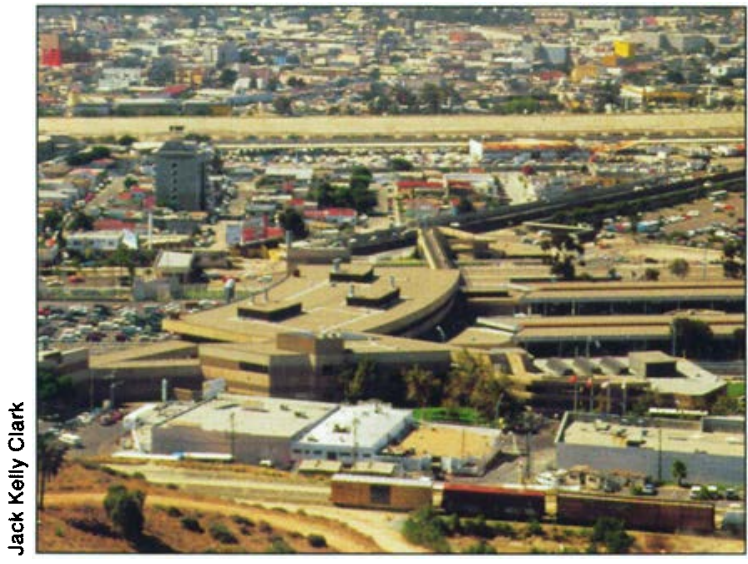

As the World Bank's director of rural development from 1994 through 1999, Alex F. McCalla led a major effort to revitalize the Bank's rural development agenda. Prior to joining the World Bank, McCalla served as dean of the UC Davis College of Agricultural and Environmental Sciences (1970-75) and founding dean for the UC Davis Graduate School of Management (197981). An agricultural economist who first joined the UC Davis faculty in 1966, he has published extensively in international trade research. After retiring from the World Bank at the end of 1999, McCalla returned to UC Davis as professor emeritus. California Agriculture Executive Editor Janet White spoke with McCalla on how improving farm productivity in developing countries can help solve problems of food supply, rural poverty and environmental degradation.

What are the most important challenges facing agriculture worldwide in the next 25 years?

The first and continuing challenge facing world agriculture is to produce enough food to feed a growing population - expected to reach 8 billion people by 2025 or 2030 and possibly 10 billion people by 2050 . Nearly all of the increase of 2 billion people in the next 25 years will be in developing countries. Urban population in those countries will double from 2 billion to 4 billion in the same period. Urbanization has significant implications for the food system.

People in rural areas depend on their own production for more than $60 \%$ of their food supply, as opposed to less than $10 \%$ for people in urban areas. Every time one person moves from a rural to the urban setting, needed market supplies must double. Further, rising incomes shift the nature of demand. A recent study by International Food Policy Research Institute forecasts a $180 \%$ increase in the demand for meat in developing countries by 2020 .

The second challenge for agriculture is to be an engine of growth and poverty reduction. Today, some $70 \%$ of the poor are still rural dwellers, and the majority draw some or all of their incomes from agricultural activities. We must develop technologies, policies and institutions to unleash agriculture's full potential as an engine of growth. This will require farmers to have access to both domestic and international markets.

The third challenge for agriculture is to create a set of technologies, incentives and policies which encourage small farmers to pay attention to the long-run stewardship of the natural resources they manage. Agriculture uses more than $70 \%$ of the world's fresh water, and much biodiversity is contained in agricultural systems. Agricultural activities influence the boundaries of forests and deserts.

Where will the needed food come from?

Expanded trade may not be the answer. Over the last 40 years, a period when the food supply doubled, on average $90 \%$ of the world's food consumption took place in the country where it was produced. If the share of grain traded doesn't change, then $90 \%$ of the increase in food production must come from the countries where the additional people will live.

Population growth between 2000 and 2030 will occur chiefly between the Tropics of Cancer and Capricorn, including most of Latin America, all of Central America and most of Mexico; all of Africa (except the North Africa Region and South Africa); the southern half of India and all of southeast Asia including Indonesia.

Tropical and subtropical farming systems are complex, highly heterogeneous, fragile, generally low in productivity and dominated by small-scale, poor farmers. And to make things more complicated, we know much less about farming systems in these regions.

The bottom line is we are going to have to do more in farming systems about which we know less and which are generally low in productivity. That makes it a much bigger challenge than aggregate numbers would suggest.

What are the major forces that will shape agriculture in the future?

The role of government will be significantly different and possibly diminished. Markets will play a much larger role, as will citizens at the 
local and regional levels. This will lead to freer trade, internally and internationally. There will be less funds to subsidize inputs, price supports, export subsidies and public-sector research.

The molecular biology revolution and its application through biotechnology, coupled with changes in intellectual-property rights, will give rise to massive increases in private-sector research investment and in proprietary science. So far the focus has been primarily on the developed countries; how far it will spread to developing countries is unclear.

Globalization and the information revolution will also mean that science and technology are truly global and therefore national agricultural strategies are less viable. Human capital, investment dollars and scientific knowledge are globally fungible, meaning a country is either part of the global knowledge system or it gets left behind.

Other events driving the future of worldwide agriculture include information technology, environmental problems including resource competition, global warming and trade liberalization.

If production needs to increase, will this occur through farm expansion or more intense cultivation?

Agriculture worldwide can be viewed as consisting of two major groups. The "extensive" areas, which are land rich and labor poor, include North America, southern South America, southern Africa and Australia as well as many countries of the former Soviet Union. The "intensive" areas, where the labor/land ratio is high, include Europe, Japan, China and India as well as many poor developing countries in Latin America, Asia and some of Africa.

In the extensively farmed areas, growers first sought technological change to replace the scarcest and most expensive factor of production - labor. Horses first replaced manpower and then tractors replaced horses. This mechanization freed up millions of acres that previously produced horse feed to produce food. The next technology adopted was biological - both improved varieties and improved agronomy followed by chemical technology after World War II, resulting in ever greater crop specialization.

The result today is that in these areas a bimodal agriculture has developed, with fewer large farms producing an increasing share of the output and much larger numbers of small and parttime farmers producing a declining share. This phenomenon is most pronounced in the United States with less than 300,000 farmers (out of a total of 1.9 million) producing more than $80 \%$ of

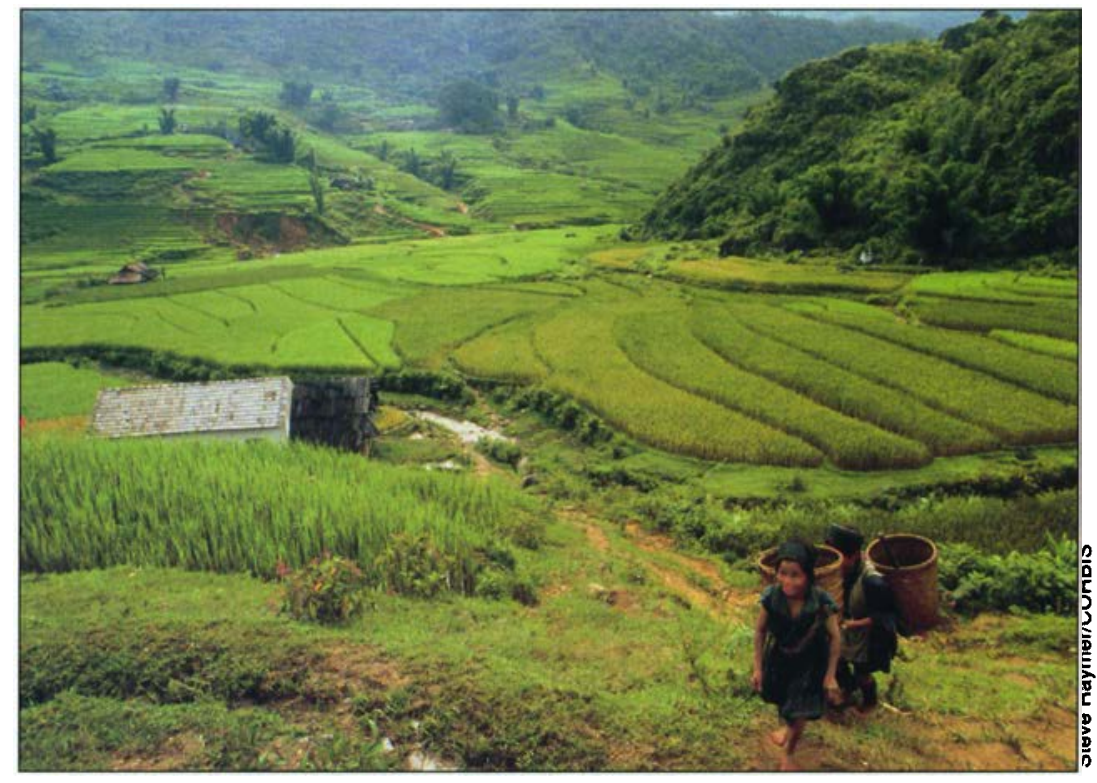

the output. In the future, these areas will continue to be bimodal, although the high level of chemical inputs used in these areas may not be sustainable.

The land-poor areas of intensive agriculture were historically characterized either by large estates and small tenant plots or small family farms. In this environment, where land is the scarcest resource, one would expect a focus on yield-increasing technology first. In both Europe and Asia the major biological and chemical innovations preceded mechanical technology. Given that both of these technologies are scale neutral but commodity specific, small farms tended to specialize. Mechanical technology came much later, and in most cases fit the smaller scale of agriculture. Agriculture in these areas is still relatively small scale, highly chemical-input intensive and tending toward more farm-level specialization. I believe that it will not become like U.S. agriculture because the relative power of external forces (such as globalization and trade liberalization) versus internal forces (such as national agricultural policies and agronomic advances) has shifted substantially in the last onethird century and will continue to shift in the next.

What scenarios do you see for the future of agriculture?

Here's the positive scenario: globalization, the information revolution and the ascendancy of markets lead to freer capital and technology flows. This allows poor countries to experience rapid, widely shared economic
Global agriculture can be divided into two groups: land rich, extensively farmed regions such as North America, southern Africa and Russia; and land poor, intensively farmed regions such as Europe and Asla. In Vietnam, Hmong farmers work terraced rice paddles.

\section{Agriculture uses more than $70 \%$ of the world's fresh water, and much biodiversity is con- tained in agricul- tural systems. Agri- cultural activities influence the boundaries of forests and deserts.}


growth. Real trade liberalization occurs. Developed countries open their markets and reduce subsidies to agriculture. Developing countries expand exports. Democratization, decentralization and less distorting domestic policies level the playing field for poor rural people, especially farmers, leading to sustained, employmentintensive rural growth.

Biotechnology is widely applied to crops of importance growing between the Tropics. Publicsector research investments lead to significant improvements in the productivity of complex tropical and subtropical farming systems. Environmental concerns and natural-resource competition stimulate the development of technologies which reduce dependence on chemical-intensive, large-scale monoculture agriculture. The result is small-scale, highly productive, multifaceted agriculture in developing countries.

The agricultures of both the older, laborintensive areas of Europe and Asia and the areas of extensive agriculture are modified to become more consistent with environmental concerns and long-term preservation of critical global resources - biodiversity, land, water and natural habitats. Finally, global warming occurs at a sufficiently slow pace that global agriculture can adapt.

This scenario is possible if we do the right things starting now.

\section{Is there a less positive scenario?}

In the alternative, less satisfying scenario, globalization leads to bigger disparities between the haves and have nots. Financial instability increases and smaller, vulnerable countries are buffeted by economic insecurity. Gains in poverty reduction are partially reversed, for example in Indonesia. Real agricultural trade liberalization fails, developed countries continue to subsidize and protect their agricultures and poor developed countries still lack access to developed-country markets. Urban elites regain (or maintain) control in developing countries, continuing to pursue policies biased against agriculture and rural areas.

Poor rural areas are left behind as democratization, decentralization and community participation run afoul of entrenched political and bureaucratic systems. The fruits of biotechnology remain primarily focused on temperate crops of global importance while public investments in agricultural research of relevance to the developing countries withers under fiscal conservatism. The result is a truly global bimodal agriculture where large-scale, input-intensive farms outside of the Tropics grow larger and more concentrated. Agribusiness keeps ahead of them on the same path they are following now. Smallscale agriculture between the Tropics languishes, leaving these latitudes more dependent on external food supplies.

\section{What are the implications for global food security?}

The positive scenario would contribute to meeting all three challenges. Food production and rural incomes would rise for countries between the Tropics. Trade liberalization and continued policy reform would contribute to poverty reduction and improved incentives for the husbandry of natural resources. Disparities in income between rural and urban, rich and poor, would be reduced and greater global stability would follow.

The consequences of the alternative scenario could be quite stark. Complex farming systems between the Tropics would not improve. Poverty, rural and urban, would deepen. Dependence on international food supplies would increase, so that poor, food-deficit countries are more vulnerable to international instability. The worst variant sees agricultural resources in rich countries diverted to producing energy and industrial products. This leads to reduced export supplies of basic cereals, causing higher and more unstable prices. This, coupled with continued protection in rich countries would lead to limited access for tropical products and generally contracting export opportunities.

Finally, if the likely impact of global warming occurs - reduced rainfall in the Tropics and sub-Tropics and more rainfall in the temperate zone - the consequences for the 2 billion more people who will live in developing countries between the Tropics, plus the 1.3 billion very poor already there, is not pleasant to contemplate.

\section{How do you think it will play out?}

All of us would like the positive scenario to emerge, but are concerned that recent trends may portend that at least some parts of the less satisfying alternative are possible. I believe it will come out somewhere in between, depending on actions yet to be taken. But the implications for the challenges facing world agriculture and global food security are significant.

If we can meet the challenge of improving the well-being of farmers by improving the profitability of agriculture, we will have a triple win situation. We can contribute to poverty reduction, improve food security and protect natural resources. 